\title{
Rainfall-Runoff Model Considering Microtopography Simulated in a Laboratory Erosion Flume
}

\author{
Hafzullah Aksoy ${ }^{1}$ - Abdullah Gedikli ${ }^{1}$. \\ N. Erdem Unal ${ }^{1} \cdot$ Murat Yilmaz $^{1} \cdot$ Ebru Eris $^{2}$. \\ Jaeyoung Yoon ${ }^{3,4} \cdot$ Gokmen Tayfur $^{5}$
}

Received: 15 December 2015 / Accepted: 11 July 2016 /

Published online: 23 July 2016

(C) Springer Science+Business Media Dordrecht 2016

\begin{abstract}
A comprehensive process-based rainfall-runoff model for simulating overland flow generated in rills and on interrill areas of a hillslope is evaluated using a laboratory experimental data set. For laboratory experiments, a rainfall simulator has been constructed together with a $6.50 \mathrm{~m} \times 1.36 \mathrm{~m}$ erosion flume that can be given adjustable slopes changing between $5 \%$ and $20 \%$ in both longitudinal and lateral directions. The model is calibrated and validated using experimental data of simulated rainfall intensities between 45 and $105 \mathrm{~mm} / \mathrm{h}$. Results show that the model is capable of simulating the flow coming from the rill and interrill areas. It is found that most of the flow occurs in the form of rill flow. The hillslope-scale model can be used for better prediction of overland flow at the watershed-scale; it can also be used as a building block for an associated erosion and sediment transport model.
\end{abstract}

Keywords Rainfall-runoff model $\cdot$ Hillslope model $\cdot$ Rill $\cdot$ Interril area $\cdot$ Rainfall simulator

\section{Introduction}

As availability of hydrological data is restricted both at temporal and spatial scales, existing data are extended both in time and space for many practical problems such as environmental protection and water resources management (Seibert 1999). Extension in time is more

Hafzullah Aksoy

haksoy@itu.edu.tr

1 Department of Civil Engineering, Istanbul Technical University, Istanbul, Turkey

2 Department of Civil Engineering, Ege University, Izmir, Turkey

3 Department of Environmental Engineering, Korea University, Sejong, South Korea

4 Program in Environmental Technology and Policy, Korea University, Sejong, South Korea

5 Department of Civil Engineering, Izmir Institute of Technology, Izmir, Turkey 
straightforward than that in space. Owing to the temporal and spatial non-uniform precipitation and also due to highly variable topography (high mountains and deep valleys) rainfall-runoff models play a crucial role in hydrology. In rainfall-runoff models, rainfall is transformed into runoff. The input data set is the rainfall and the output is the discharge at the outlet of the catchment (Minns and Hall 1996).

Rainfall-runoff models used in hydrology can be classified as empirical models, conceptual models and process-based models (Singh and Woolhiser 2002; Aksoy and Kavvas 2005). An empirical rainfall-runoff model can be constructed based on existing data. Also conceptual models and process-based models as well as soft computational methods such as artificial neural networks (Minns and Hall 1996; Lin and Chen 2004) or fuzzy logic (Hundecha et al. 2001) are available. Conceptual models have parameters not measurable either at laboratory or at field. Such models require calibration, the tuning of the model parameters, which can either be performed manually by a trial-and-error adjustment through a visual judgement or automatically by a search scheme using a numerical measure of goodness-of-fit (Madsen 2000).

An unsteady and distributed rainfall-runoff model can serve for the extension of hydrological data. A rainfall-runoff model that can be used for this aim may be based on a lumped representation of the physical process, flow from the catchment. A few example to be mentioned are the Sacramento model (Burnash 1995), the Tank model (Sugawara 1995), the HBV model (Bergström 1995), the TOPMODEL (Beven and Kirkby 1979), and the WEHY model (Kavvas et al. 2004, 2006). Hillslope-scale rainfall-runoff models can be used as a ground for watershed-scale models (Giakoumakis and Tsakiris 2001; Yoon et al. 2014). They produce input data for sediment transport models that can be extended to pollutant or solute transport models.

Runoff is generated once either infiltration or saturation is exceeded. The former points the Hortonian approach while the latter is based on the variable source area concept (Zollweg et al. 1996). For an unlimited success, a rainfall-runoff model should define the hydrological response of the catchment effectively, without being too complex and over-parameterized. Hydrologic process in the catchment should be accounted for by avoiding the overparameterization problem through model simplification which is allowed in models and is found useful as long as the essential hydrologic behaviour of the catchment is retained (Post and Jakeman 1999).

In this study, a rainfall-runoff model using micro-topographical details of a hillslope in hydrological watersheds is developed by considering the rilling structure of the land surface. The model is based on a two-dimensional sketch and uses a rainfall simulator data generated at laboratory scale. The model is introduced below together with rainfall simulator experiments from which data are extracted for the calibration and validation stages explained next. It is seen that the developed model can be a ground for a future generation of rainfall-runoff models as well as nutrient and pollutant transport through the sediment particles moving within the flow.

\section{Microtopography Over The Hillslope}

In Fig. 1, a hillslope with its microtopographical features is given. Considering Fig. 1, it is seen that rainfall over an interrill area turns into runoff over the interrill area (Region 1 in Fig. 2) and flows towards rills. When the runoff reachs a rill (Line 2 in Fig. 2) it joins the runoff in the rill to run further downstream to the channel (Line 3 in Fig. 2). The flow joins, in the channel, to the channel flow to run further downstream to the receiving water bodies (Point 4 in Fig. 2). 


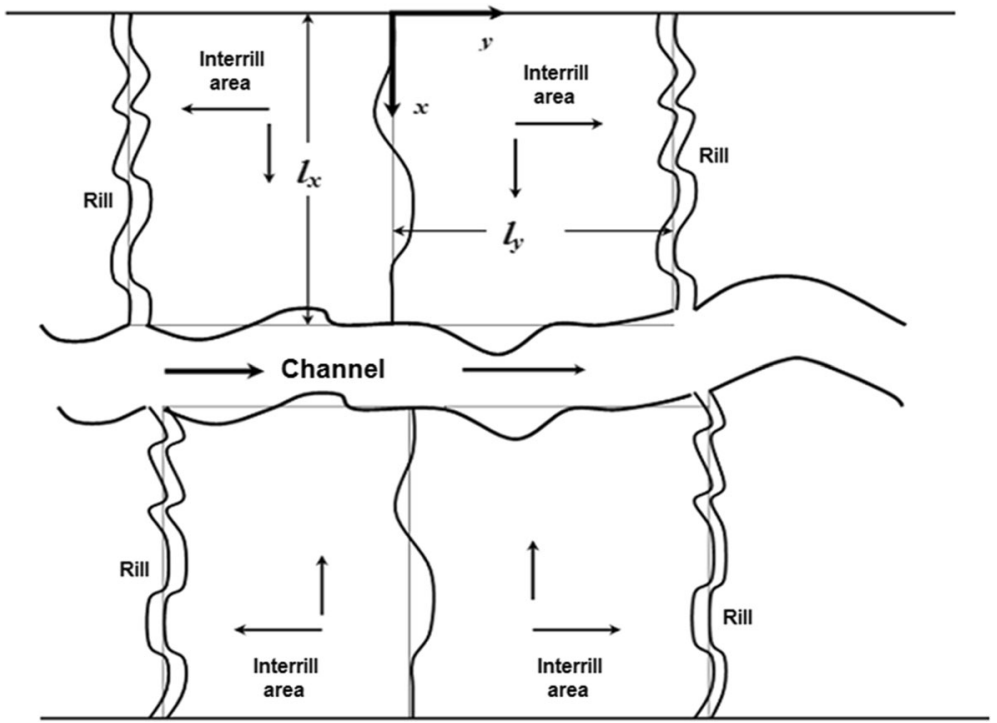

Fig. 1 Microtopographical scheme over the hillslope used for the 2-dimensional model

Runoff over interrill area (Region 1 in Fig. 2) might reach the channel (Line 3 in Fig. 2) directly without getting the rill (Line 2 in Fig. 2) depending on the lateral slope.

\section{Hydrological Model}

Using the microtopography over the hillslope, a two-dimensional rainfall-runoff model was developed in this study. The model is process-based, deterministic, and it uses the conservation

Fig. 2 Layout of interrill area, rill and channel; microtopographical scheme over the hillslope

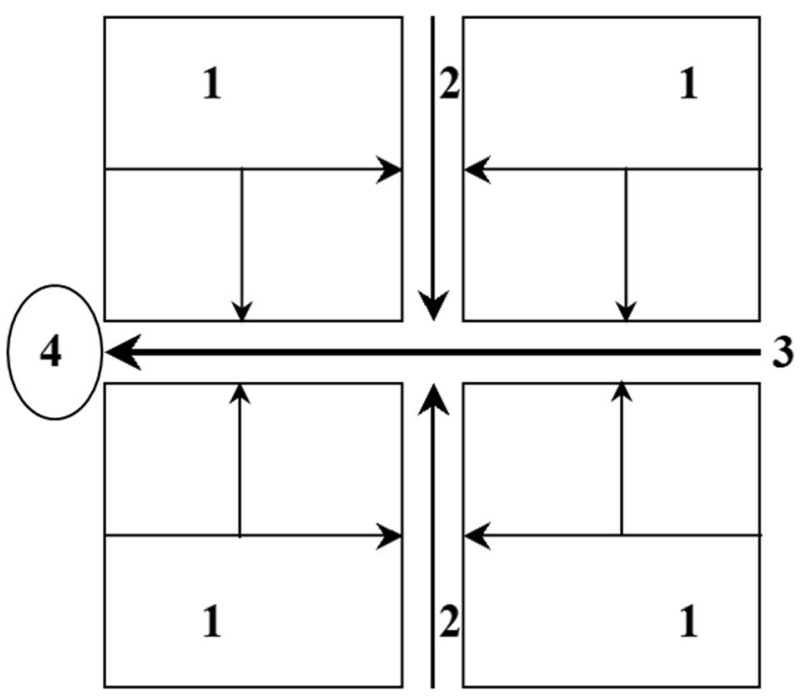


of mass, simplified with kinematic wave appraoch. It has two components, one for the interrill area flowing into the rill, and another for the rill itself.

\subsection{Interrill Area Hydrological Model}

The two-dimensional unsteady state continuity equation for the flow of an incompressible fluid over a pervious surface is given by

$$
\frac{\partial h}{\partial t}+\frac{\partial(u h)}{\partial x}+\frac{\partial(v h)}{\partial y}=r-f
$$

where $h$ is flow depth [L], $t$ time [T], $u$ and $v$ flow velocities $\left[\mathrm{LT}^{-1}\right]$ at directions $x$ and $y$, respectively, $x$ longitudinal distance $[\mathrm{L}], y$ lateral distance $[\mathrm{L}], r$ rainfall intensity $\left[\mathrm{LT}^{-1}\right]$, and $f$ infiltration rate $\left[\mathrm{LT}^{-1}\right]$. Using unit width discharge $(q)\left[\mathrm{L}^{2} \mathrm{~T}^{-1}\right]$ and taking cross-section average velocity $V\left[\mathrm{LT}^{-1}\right]$ led to

$$
q=V h
$$

When the discharges passing through unit-width cross-sections perpendicular to directions $x$ and $y$ are denoted by $q_{x}$ and $q_{y}$, respectively, Eq. 1 turns into

$$
\frac{\partial h}{\partial t}+\frac{\partial q_{x}}{\partial x}+\frac{\partial q_{y}}{\partial y}=r-f
$$

Flow depth of overland flow $(h)$ is quite small compared to the width that allows one to make a wide channel assumption ( $R=h$, where $R$ is the hydraulic radius). Considering Chezy roughness coefficient $C\left[\mathrm{~L}^{1 / 2} \mathrm{~T}^{-1}\right]$ for friction, one would obtain

$$
\frac{\partial h}{\partial t}+k_{x} \frac{\partial h^{3 / 2}}{\partial x}+k_{y} \frac{\partial h^{3 / 2}}{\partial y}=r-f
$$

where,

$$
\begin{aligned}
& k_{x}=\frac{C_{z} S_{x}^{1 / 2}}{\left[1+\left(\frac{S_{y}}{S_{x}}\right)^{2}\right]^{1 / 4}}=\frac{C_{z} S_{x}}{\left(S_{x}^{2}+S_{y}^{2}\right)^{1 / 4}}=C_{z} \frac{S_{x}}{S^{1 / 2}} \\
& k_{y}=\frac{C_{z} S_{y}^{1 / 2}}{\left[1+\left(\frac{S_{x}}{S_{y}}\right)^{2}\right]^{1 / 4}}=\frac{C_{z} S_{y}}{\left(S_{x}^{2}+S_{y}^{2}\right)^{1 / 4}}=C_{z} \frac{S_{y}}{S^{1 / 2}}
\end{aligned}
$$

In Eqs.3-4, $S_{x}$ and $S_{y}$ are slopes in directions $x$ and $y$, respectively (Govindaraju et al. 1992; Tayfur and Kavvas 1998; Tayfur 2007). The resulting slope $(S)$ can be given, as defined in Tayfur (2001), by

$$
S=\sqrt{S_{x}^{2}+S_{y}^{2}}
$$

It should be noted that variables in Eq.4 are all time- and space-dependent. By defining a new variable $Y$ as 


$$
Y=\sin \frac{\pi y}{2 l_{y}}
$$

flow depth $h(x, y, t)$ in Eq.4 can then be given by

$$
h(x, y, t)=Y(y) h(x, t)
$$

This converts $h(x, y, t)$ to $h(x, t)$ reducing number of independent variables on which flow depth depends, to two from three. Flow depth becomes independent of lateral distance $y$ by introducing the variable $Y$. Referencing Fig. $1 Y=1$ for $y=l_{y}$ where interrill area reaches the rill, and

$$
h\left(x, l_{y}, t\right)=h(x, t)
$$

is obtained. Inserting Eq.9 into Eq.4 ends up with

$$
\frac{\partial(Y h)}{\partial t}+k_{x} \frac{\partial(Y h)^{3 / 2}}{\partial x}+k_{y} \frac{\partial(Y h)^{3 / 2}}{\partial y}=r-f
$$

Taking derivatives by considering that $Y$ is a function of $y$ only while $h$ is a function of both $x$ and $t$

$$
\frac{\partial h}{\partial t} Y+\frac{3}{2} k_{x} h^{1 / 2} \frac{\partial h}{\partial x} Y^{3 / 2}+k_{y} h^{3 / 2} \frac{d Y^{3 / 2}}{d y}=r-f
$$

is achieved. Integrating Eq.12 at direction $y$ at the interval $\left(0, l_{y}\right)$ results in

$$
\frac{\partial h}{\partial t} \int_{0}^{l_{y}} Y d y+k_{x} \frac{\partial h^{3 / 2}}{\partial x} \int_{0}^{l_{y}} Y^{3 / 2} d y+k_{y} h^{3 / 2} \int_{0}^{l_{y}} \frac{d Y^{3 / 2}}{d y} d y=(r-f) \int_{0}^{l_{y}} d y
$$

Integration terms in Eq.13 are calculated as follows:

$$
\begin{gathered}
\int_{0}^{l_{y}} Y d y=\frac{2}{\pi} l_{y} \\
\int_{0}^{l_{y}} Y^{3 / 2} d y=\frac{1}{\sqrt{\pi}} \frac{\Gamma\left(\frac{5}{4}\right)}{\Gamma\left(\frac{7}{4}\right)} l_{y}=0.556418 l_{y} \\
\int_{0}^{l_{y}} \frac{d}{d y} Y^{3 / 2} d y=1
\end{gathered}
$$




$$
\int_{0}^{l_{y}} d y=l_{y}
$$

When Eqs.14a-d are inserted into Eq.13

$$
\frac{\partial h}{\partial t}+\frac{\pi}{2} 0.556418 k_{x} \frac{\partial h^{3 / 2}}{\partial x}+\frac{\pi}{2 l_{y}} k_{y} h^{3 / 2}=\frac{\pi}{2}(r-f)
$$

is obtained. By further deriving the second term in the left hand side of Eq.15

$$
\frac{\partial h}{\partial t}+\left(1.31103 k_{x}\right) h^{1 / 2} \frac{\partial h}{\partial x}+\left(1.5708 \frac{k_{y}}{l_{y}}\right) h^{3 / 2}=1.5708(r-f)
$$

is achieved.

Eq.16 was derived by using the mass conservation of rainfall-runoff process taking place over an infiltrating interrill area. Flow is considered two-dimensional. It is noted that, the model as given in Eq.16 takes only changes in longitudinal direction into account although it was derived from a two-dimensional control volume. The model uses the variability with time as well. The model, Eq.16, can be organized as

$$
\frac{h_{i}-H_{i}}{\Delta \mathrm{t}}+\left(1.31103 k_{x}\right) h_{i}^{1 / 2} \frac{h_{i}-h_{i-1}}{\Delta \mathrm{x}}+\left(1.5708 \frac{k_{y}}{l_{y}}\right) h_{i}^{3 / 2}=1.5708(r-f)
$$

by using the backward finite difference scheme and considering $h_{i}$ as flow depth at point $i$ of the current time, and $H_{i}$ flow depth at point $i$ of the previous time. Eq.17 can be solved by numerical schemes.

\subsection{Rill Hydrological Model}

A one-dimensional flow is considered in the rill for which a triangle cross-section is assumed (Fig. 3). Continuity equation for the one-dimensional flow of an incompressible fluid is given by

$$
\frac{\partial A}{\partial t}+\frac{\partial Q}{\partial x}=q_{l}+q_{l R}
$$

where $A$ is cross-section area $\left[\mathrm{L}^{2}\right], t$ time [T], $Q$ flow discharge $\left[\mathrm{L}^{3} \mathrm{~T}^{-1}\right], x$ longitudinal distance along the hillslope [L], $y$ lateral distance of the hillslope [L], $q_{l}$ direct net rainfall on the rill $\left[\mathrm{L}^{2} \mathrm{~T}^{-1}\right]$ and $q_{I R}$ flow coming from interrill area along the unit length of the rill $\left[\mathrm{L}^{2} \mathrm{~T}^{-1}\right]$. Source terms in Eq.18 are defined as

$$
\begin{gathered}
q_{l}=(r-f) b \\
q_{l R}=q_{y}^{l R}\left(x, l_{y}, t\right)
\end{gathered}
$$

in which $r$ and $f$, as defined before, are rainfall intensity [LT ${ }^{-1}$ ] and infiltration rate [LT ${ }^{-1}$ ], respectively, $b$ width of the rill [L] (Fig. 3). In Eq.20, $q_{y}^{l R}$ is the unit width discharge [LT ${ }^{-1}$ ] 


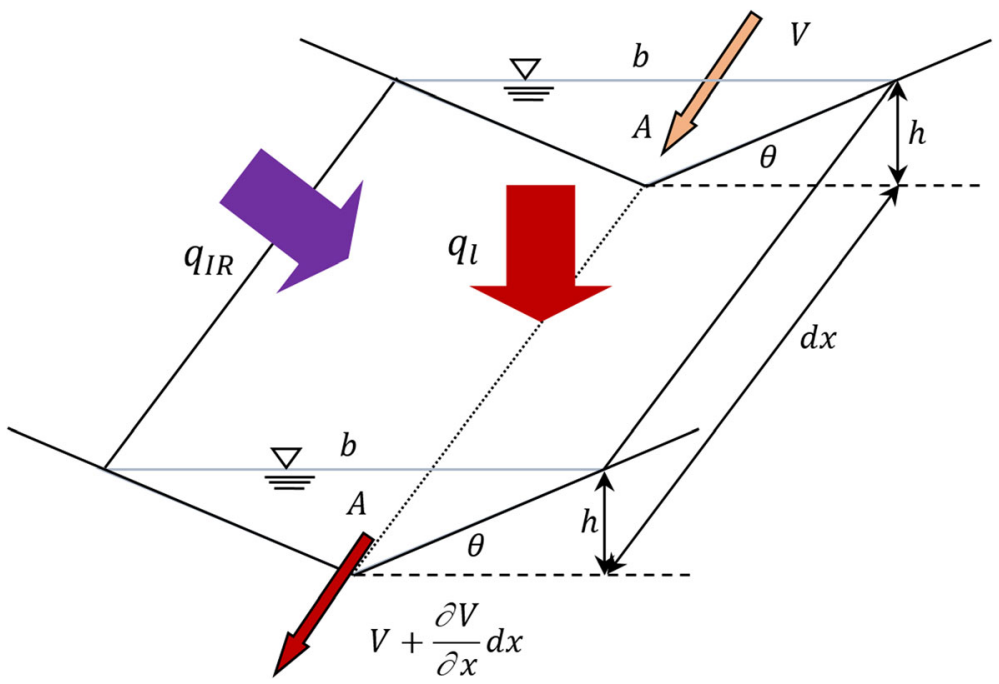

Fig. 3 Control volume used for mass conservation in rill

coming from the interril area at the lateral distance $y=l_{y}$ where interrill area contribution reaches the rill.

From the geometry of the rill, Eq.19 becomes

$$
q_{l}=(r-f) \frac{2 h}{\tan \theta}
$$

Again considering the geometry of the rill (Fig. 3) and using Chezy equation for the flow velocity, continuity equation can be written as

$$
Q=C_{z} \sqrt{\frac{S_{x}}{2 \cos \theta}} h^{5 / 2}
$$

Derivatives in Eq.18 are taken by the chain rule to obtain

$$
\frac{\partial A}{\partial h} \frac{\partial h}{\partial t}+\frac{\partial Q}{\partial h} \frac{\partial h}{\partial x}=q_{l}+q_{l R}
$$

Taking derivatives by considering the geometry of the rill and using Eqs.21-22 give the final equation as

$$
2 h\left(\frac{\partial h}{\partial t}-(r-f)\right)+\left(\frac{5}{2 \sqrt{2}} C_{z} \sqrt{S_{x} \cos \theta}\right) h^{3 / 2} \frac{\partial h}{\partial x}=q_{l R} \tan \theta
$$

Considering that $h_{i}$ is flow depth at point $i$ of the current time, and $H_{i}$ flow depth at point $i$ of the previous time, as defined in the interrill area part of the model; additionally, $q_{l R, i}$ is the unit width discharge arriving to the rill from the interrill area at point $i$ of the current time. The 
model, Eq.24, is organized by using the backward finite difference scheme under the above definitions as

$$
\begin{aligned}
& \left(\frac{5}{2 \sqrt{2}} C_{z} \sqrt{S_{x} \cos \theta} \frac{1}{\Delta \mathrm{x}}\right) h_{i}^{5 / 2}+\left(\frac{2}{\Delta \mathrm{t}}\right) h_{i}^{2}-\left(\frac{5}{2 \sqrt{2}} C_{z} \sqrt{S_{x} \cos \theta} \frac{h_{i-1}}{\Delta \mathrm{x}}\right) h_{i}^{3 / 2} \\
& -2\left(\frac{H_{i}}{\Delta \mathrm{t}}+(r-f)\right) h_{i}+q_{l R, i} \tan \theta=0
\end{aligned}
$$

to be solved by numerical methods.

\section{Infiltration Model}

For the infiltration into the soil due to rainfall, the model given by Horton (1933) as

$$
f(t)=f_{c}+\left(f_{0}-f_{c}\right) e^{-k_{h} t}
$$

was used, in which $f_{0}$ is the initial infiltration capacity $\left[\mathrm{LT}^{-1}\right]$ of the soil, $f_{c}$ the limit infiltration capacity of the soil $\left[\mathrm{LT}^{-1}\right]$ and $k_{h}$ the recession parameter $\left[\mathrm{T}^{-1}\right]$ (Fig. 4 ). Less infiltration rate than the infiltration capacity of the soil is observed for rainfall intensities under the infiltration capacity of the soil. In this case, the standard infiltration curve is replaced with a shifted infiltration curve. With introducing $\tau$ as a new time variable by

$$
t=t_{s}+\tau
$$

and using the initial condition

$$
f(\tau=0)=r
$$

the shifted Horton infiltration equation is obtained as

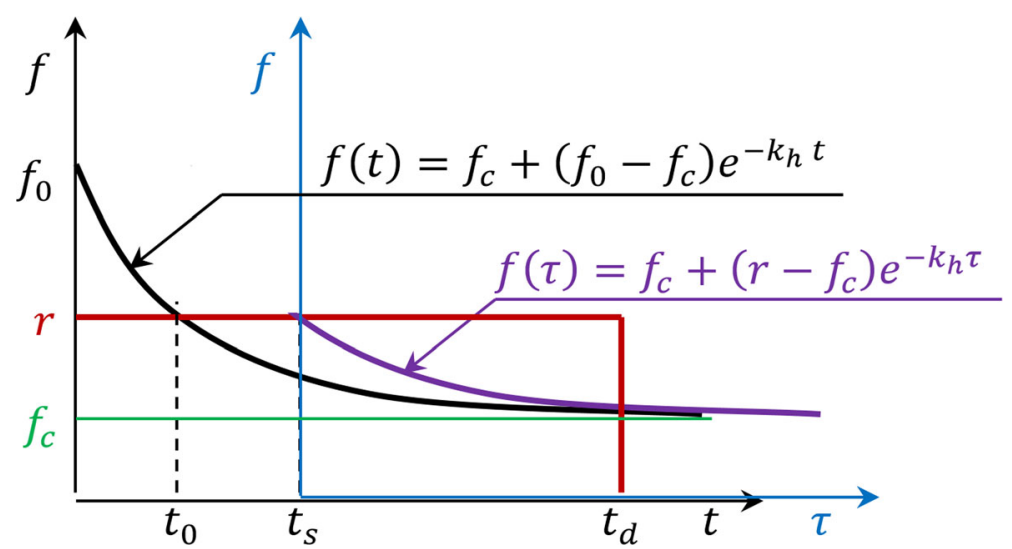

Fig. 4 Horton infiltration model 


$$
f(\tau)=f_{c}+\left(r-f_{c}\right) e^{-k_{h} \tau}
$$

The accumulated infiltration is obtained by the integration of Eq.29 as

$$
F(\tau)=\int_{0}^{\tau} f d t=f_{c} \tau+\frac{\left(r-f_{c}\right)}{k_{h}}\left(1-e^{-k_{h} \tau}\right)
$$

It is important to note that the shifted Horton equation reduces number of parameters to two $\left(f_{c}, k_{h}\right)$ from three $\left(f_{0}, f_{c}, k_{h}\right)$ by demonstrating that $f_{0}$ in Eq.26 is not further needed.

\section{Experimental Setup and Measurements}

Figure 5 describes the experimental setup composed of a $6.50 \mathrm{~m} \times 1.36 \mathrm{~m}$ erosion flume with a depth of $17 \mathrm{~cm}$. It is equipped with four or five VeeJet nozzles spaced at $125-145 \mathrm{~cm}$, depending on the rainfall intensity, to serve as the rainfall simulator over the flume. Slope of the flume can be adjusted at both longitudinal and lateral directions.

In order to take the effect of microtopography (the rilling) into account, in each experiment, the sand-filled flume was given an initial topography with a triangular cross-section rill, $2 \mathrm{~cm}$ deep and $26 \mathrm{~cm}$ wide, longitudinally pre-formed in the right hand side of the flume before the rainfall is applied (see Fig. 5, right panel). In Fig. 6, it is seen that most of the interrill area contributes flow in the rill and a small portion of the interrill area flows directly into the channel. Therefore, on the right hand side of Fig. 6, two outlets were formed on the flume. Outlet (1) is used for collecting flow from the rill while outlet (2) collects flow directly from the interrill area to the channel. Granting that contribution of flow to the channel coming directly from the interrill area is minor, measurement is still needed for mass conservation purposes in calibrating the model.

The flume is filled with a uniform granular medium size sand of $0.45 \mathrm{~mm}$ median diameter to be exposed to rainfall with different intensities $(45,65,85,105 \mathrm{~mm} / \mathrm{h})$.
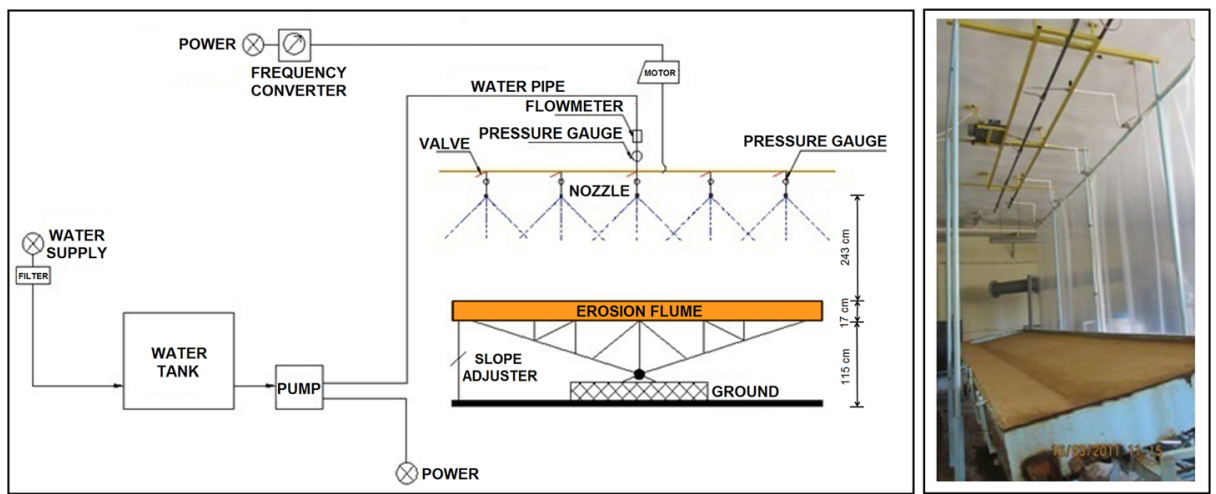

Fig. 5 Sketch of the rainfall simulator and erosion flume (Aksoy et al. 2012) 


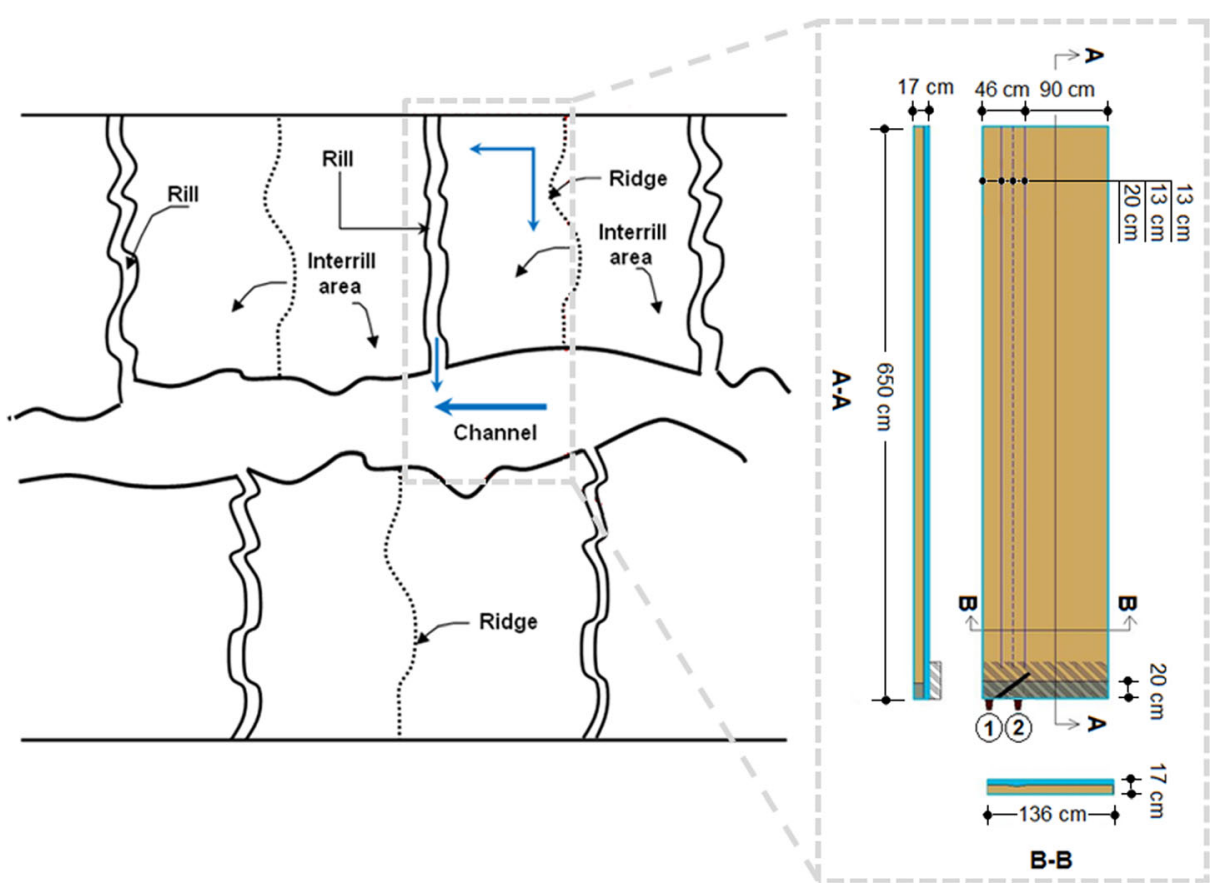

Fig. 6 Schematic description of microtopography in a watershed and plan view of the erosion flume (Aksoy et al. 2012)

The rainfall intensity is set at the desired level by adjusting the discharge pumped up into the rainfall simulator. For each of the rainfall intensity, 10 experiments are performed; forty experiments in total, considering combinations of lateral and longitudinal slopes $(5,10,15,20 \%)$ based on the assumption that longitudinal slope can never be milder than the lateral slope. Rainfall intensity is changed by replacing nozzles when 10 combinations of slopes are made complete. Having all combinations of slopes and rainfall intensities completed a new series of experiments can be performed by filling the erosion flume with another type of soil.

In experiments, a while after rainfall application starts, soil becomes saturated and surface flow is observed in the rill. No measurement is taken until surface flow reaches outlet (1) of the flume after which rainfall is applied for $15 \mathrm{~min}$. Measurements are taken from both outlets of the flume by means of measurement cups every $1 \mathrm{~min}$ or at as short time intervals as $10-15 \mathrm{~s}$ depending on how fast the cups are filled. Measurements are continued to be taken for 10 more minutes after the rainfall is ceased so that the recession curve of the hydrograph can be constructed. The total length of time for measurements becomes 25 min including the ascension part, steady-state part and recession part of the hydrographs constructed by considering the total volume collected at the two outlets of the flume.

Further details of the experimental setup, observations, measurements, and the use of experimental data can be obtained from a series of publications (Aksoy et al. 2012, 2013; Arguelles et al. 2013, 2014; Mallari et al. 2015a, 2015b). 


\section{Calibration of Model Parameters}

The rainfall-runoff model has four parameters as listed in Table 1, which are Chezy coefficients for the interrill area and the rill $\left(C_{Z}\right.$ and $\left.C_{Z R}\right)$, limit infiltration capacity and recession parameter of the infiltration model $\left(f_{c}\right.$ and $\left.k_{h}\right)$. Model parameters are calibrated using above described experimental data through the least square method to minimize the difference between the measured and calculated discharges such that the measured hydrograph is best approximated. Calibration is based on a set of 32 out of 40 experimental data taken from the rainfall simulations detailed above (Aksoy et al. 2013). Eight experiments are used for the validation of the model.

Through the calibration, it is first checked if the total flow is preserved. At the same time, the time-varying structure of the hydrograph is taken into consideration; i.e., the rising limb, steady-state stage (when exists) and the recession curve of the hydrograph are paid a particular attention. This is achieved by the calibration of the rainfall-runoff model parameters $\left(C_{Z}, C_{Z R}, f_{c}, k_{h}\right)$, calibrated as in Table 2.

It is an obvious challenge that the calibration parameters in Table 2 vary within a wide range. As can be seen, the parameters have various values; e.g., $f_{c}$ changes within an order of magnitude. The hydrographs were generated by the model using the calibrated parameters. Figure 7 shows several examples of well simulated hydrographs for the calibration. It is seen from the chosen examples that the model is able to catch the rising limb, the steady state period (when exists) and the recession curve of the hydrographs.

The calibration procedure is carried out in two steps: First; each of 32 hydrographs is used seperately for the calibration; i.e., single set of optimal (calibrated) parameter values is obtained for each hydrograph. Then, from the 32 sets of calibrated values, a new single set is obtained, as a representative set, for all hydrographs as presented in the validation stage of the model.

\section{Model Validation}

An obvious challenge seen in Table 2 is that the parameters vary within a wide range as stated above. The proper calibration procedure, for the same soil and roughness condition, requires that there should be one single set of representative values for the calibration parameters for all the experimental runs. Therefore, the infiltration parameters are set at single values by taking simply the average of calibrated values in Table 2. On the other hand, Chezy roughness parameters for the interrill area and the

Table 1 Model parameters

\begin{tabular}{lll}
\hline Parameter & Dimension $\left[\mathrm{M}^{\mathrm{x}} \mathrm{L}^{\mathrm{y}} \mathrm{T}^{\mathrm{z}}\right]$ & Definition \\
\hline$C_{Z}$ & $\mathrm{~L}^{1 / 2} \mathrm{~T}^{-1}$ & Chezy coefficient in interrill area \\
$C_{Z R}$ & $\mathrm{~L}^{1 / 2} \mathrm{~T}^{-1}$ & Chezy coefficient in rill \\
$f_{c}$ & $\mathrm{LT}^{-1}$ & Limit infiltration capacity \\
$k_{h}$ & $\mathrm{~T}^{-1}$ & Infiltration model recession parameter
\end{tabular}


Table 2 Calibration of model parameters

\begin{tabular}{llllllll}
\hline$r(\mathrm{~mm} / \mathrm{h})$ & $S_{y}(\%)$ & $S_{x}(\%)$ & $S(\%)$ & $C_{Z}\left(\mathrm{~m}^{1 / 2} / \mathrm{s}\right)$ & $C_{Z R}\left(\mathrm{~m}^{1 / 2} / \mathrm{s}\right)$ & $f_{c}(\mathrm{~mm} / \mathrm{h})$ & $k_{h}(1 / \mathrm{s})$ \\
\hline 45 & 5 & 5 & 7.07 & 5.81 & 8.53 & 0.81 & $1.39 \mathrm{E}-02$ \\
45 & 5 & 10 & 11.18 & 6.34 & 7.44 & 10.04 & $3.10 \mathrm{E}-03$ \\
45 & 5 & 20 & 20.62 & 0.88 & 5.20 & 0.50 & $5.74 \mathrm{E}-03$ \\
45 & 10 & 10 & 14.14 & 0.95 & 6.72 & 0.50 & $5.10 \mathrm{E}-03$ \\
45 & 10 & 15 & 18.03 & 2.40 & 5.80 & 0.50 & $2.49 \mathrm{E}-03$ \\
45 & 15 & 15 & 21.21 & 0.60 & 5.00 & 3.02 & $4.10 \mathrm{E}-03$ \\
45 & 15 & 20 & 25.00 & 0.44 & 4.10 & 0.50 & $5.55 \mathrm{E}-03$ \\
45 & 20 & 20 & 28.28 & 0.29 & 3.30 & 1.55 & $5.48 \mathrm{E}-03$ \\
65 & 5 & 5 & 7.07 & 5.59 & 6.09 & 4.43 & $9.10 \mathrm{E}-03$ \\
65 & 5 & 10 & 11.18 & 2.99 & 9.58 & 3.92 & $3.60 \mathrm{E}-03$ \\
65 & 5 & 20 & 20.62 & 0.82 & 3.59 & 0.50 & $1.60 \mathrm{E}-02$ \\
65 & 10 & 10 & 14.14 & 2.50 & 9.13 & 4.32 & $2.70 \mathrm{E}-03$ \\
65 & 10 & 15 & 18.03 & 3.14 & 4.89 & 2.79 & $2.91 \mathrm{E}-03$ \\
65 & 15 & 15 & 21.21 & 1.15 & 7.19 & 0.50 & $6.16 \mathrm{E}-03$ \\
65 & 15 & 20 & 25.00 & 0.65 & 3.29 & 0.50 & $3.88 \mathrm{E}-03$ \\
65 & 20 & 20 & 28.28 & 0.55 & 2.85 & 0.50 & $4.53 \mathrm{E}-03$ \\
85 & 5 & 5 & 7.07 & 5.14 & 8.28 & 7.16 & $4.10 \mathrm{E}-03$ \\
85 & 5 & 10 & 11.18 & 5.94 & 8.53 & 0.50 & $1.72 \mathrm{E}-03$ \\
85 & 5 & 20 & 20.62 & 1.60 & 5.09 & 0.50 & $7.53 \mathrm{E}-03$ \\
85 & 10 & 10 & 14.14 & 1.49 & 5.11 & 0.50 & $2.09 \mathrm{E}-03$ \\
85 & 10 & 15 & 18.03 & 1.41 & 5.04 & 0.50 & $2.20 \mathrm{E}-03$ \\
85 & 15 & 15 & 21.21 & 1.98 & 4.19 & 0.50 & $2.56 \mathrm{E}-03$ \\
85 & 15 & 20 & 25.00 & 1.31 & 3.09 & 4.76 & $4.82 \mathrm{E}-03$ \\
85 & 20 & 20 & 28.28 & 1.17 & 2.70 & 7.70 & $3.97 \mathrm{E}-03$ \\
105 & 5 & 5 & 7.07 & 3.92 & 8.28 & 0.50 & $1.69 \mathrm{E}-03$ \\
105 & 5 & 10 & 11.18 & 5.59 & 4.09 & 0.50 & $4.12 \mathrm{E}-03$ \\
105 & 5 & 20 & 20.62 & 3.59 & 3.09 & 0.50 & $2.81 \mathrm{E}-03$ \\
105 & 10 & 10 & 14.14 & 2.84 & 5.84 & 10.62 & $1.83 \mathrm{E}-02$ \\
105 & 10 & 15 & 18.03 & 2.60 & 5.09 & 0.50 & $2.29 \mathrm{E}-03$ \\
105 & 15 & 15 & 21.21 & 1.28 & 5.09 & 4.29 & $5.55 \mathrm{E}-03$ \\
105 & 15 & 20 & 25.00 & 2.28 & 3.18 & 0.50 & $5.56 \mathrm{E}-03$ \\
105 & 20 & 20 & 28.28 & 1.60 & 2.47 & 0.59 & $2.31 \mathrm{E}-03$ \\
\hline & & & & & & &
\end{tabular}

rill were regressed on rainfall intensity and slope by using the genetic algorithm, a nonlinear search and optimization technique (Goldberg 1989; Tayfur 2012), as

$$
\begin{gathered}
C_{Z}=2.571+0.0522 r-0.2047 S \\
C_{Z R}=5.896+0.0257 r-0.1566 S
\end{gathered}
$$

Eqs.31-32 state that the Chezy roughness coefficient increases with rainfall intensity and decreases with topographical slope. This can possibly be related to the ratio 

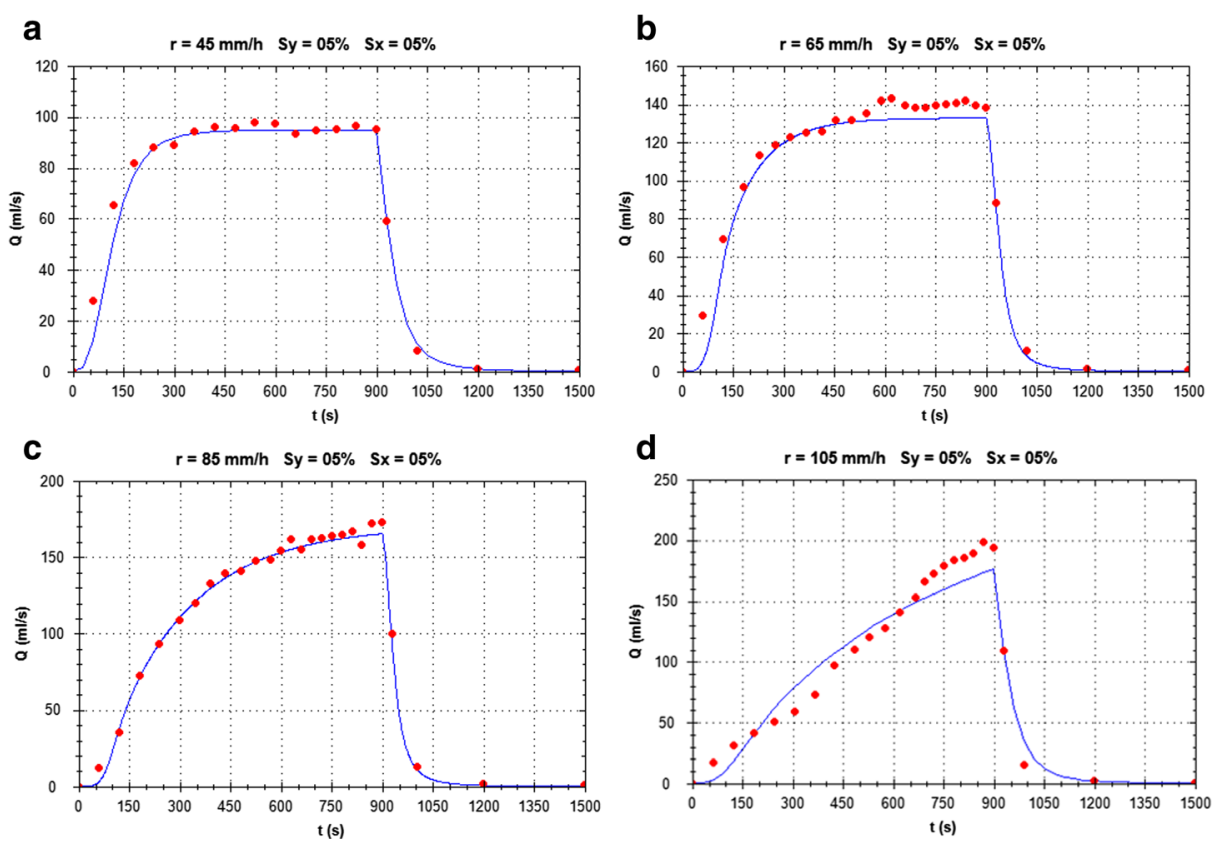

Fig. 7 Calibrated hydrographs against measured hydrographs for (a) $r=45 \mathrm{~mm} / \mathrm{h}, S_{y}=5 \%, S_{x}=5 \%$; (b) $r=65 \mathrm{~mm} / \mathrm{h}, S_{y}=5 \%, S_{x}=5 \% ;(\mathbf{c}) r=85 \mathrm{~mm} / \mathrm{h}, S_{y}=5 \%, S_{x}=5 \%$; (d) $r=105 \mathrm{~mm} / \mathrm{h}, S_{y}=5 \%, S_{x}=5 \%$ (Parameters used for each experiment are as in Table 2)

of the flow depth to the roughness of the soil; the higher the ratio, the higher the coefficient; i.e., in other words, faster flow is observed with increasing ratio. Averaged values of $f_{c}$ and $k_{h}$, and regressed values of $C_{Z}$ and $C_{Z R}$ are given in Table 3. Hydrographs validated with parameters in Table 3 are given in Fig. 8 from which it can be said that the hydrologic model performs satisfactorily due to the fact that the model is not expected to perform as good as in the calibration stage.

\section{Conclusions}

A two-dimensional unsteady-state process-based mathematical model for simulating overland flow generated in rills and on interrill areas over a hillslope is developed and evaluated using a comprehensive data set gathered from a laboratory experimental setup of a flume having lateral and longitudinal slopes changing between $5 \%$ and $20 \%$, and exposed to rainfall intensities between 45 and $105 \mathrm{~mm} / \mathrm{h}$ with the use of nozzles in the rainfall simulator. The model is calibrated and validated using the experimental measurements. Infiltration was simulated by the Horton equation for which parameters are fixed after the calibration with 32 experiments. Roughness parameters of the model were regressed on rainfall intensity and topographical slope by genetic algorithm. Validated hydrographs show that the developed model is capable of simulating the total outflow of the interrill areas and the rill over a hilllslope. Therefore, the developed model can be used as a ground for prediction of overland flow at hillslope-scale and be extended to watershed-scale. Outputs of the model can be used as inputs into an erosion and sediment transport model to be developed. 
Table 3 Experimental characteristics and parameters used for the validation of the model

\begin{tabular}{llllllll}
\hline$r(\mathrm{~mm} / \mathrm{h})$ & $S_{y}(\%)$ & $S_{x}(\%)$ & $S(\%)$ & $C_{Z}\left(\mathrm{~m}^{1 / 2} / \mathrm{s}\right)$ & $C_{Z R}\left(\mathrm{~m}^{1 / 2} / \mathrm{s}\right)$ & $f_{c}(\mathrm{~mm} / \mathrm{h})$ & $k_{h}(1 / \mathrm{s})$ \\
\hline 45 & 5 & 15 & 15.81 & 1.68 & 4.58 & 2.34 & $5.19 \mathrm{E}-03$ \\
45 & 10 & 20 & 22.36 & 0.34 & 3.55 & 2.34 & $5.19 \mathrm{E}-03$ \\
65 & 5 & 15 & 15.81 & 2.73 & 5.09 & 2.34 & $5.19 \mathrm{E}-03$ \\
65 & 10 & 20 & 22.36 & 1.39 & 4.06 & 2.34 & $5.19 \mathrm{E}-03$ \\
85 & 5 & 15 & 15.81 & 3.77 & 5.60 & 2.34 & $5.19 \mathrm{E}-03$ \\
85 & 10 & 20 & 22.36 & 2.43 & 4.58 & 2.34 & $5.19 \mathrm{E}-03$ \\
105 & 5 & 15 & 15.81 & 4.82 & 6.12 & 2.34 & $5.19 \mathrm{E}-03$ \\
105 & 10 & 20 & 22.36 & 3.47 & 5.09 & 2.34 & $5.19 \mathrm{E}-03$ \\
\hline
\end{tabular}

Compared to the existing models the novelty in the proposed model comes from the fact that (i) a detailed microtopography has been introduced in the rainfall-runoff generation mechanism over the hillslope; (ii) both lateral and longitudinal topographical slopes have been used in the model development, (iii) the Horton model has been modified by shifting the standard infiltration curve to reduce the number of parameters, (iv) two out of four calibration parameters in the model are set at constant values while another two are adjusted using regression equations based on physical variables; rainfall intensity and topographical slope.
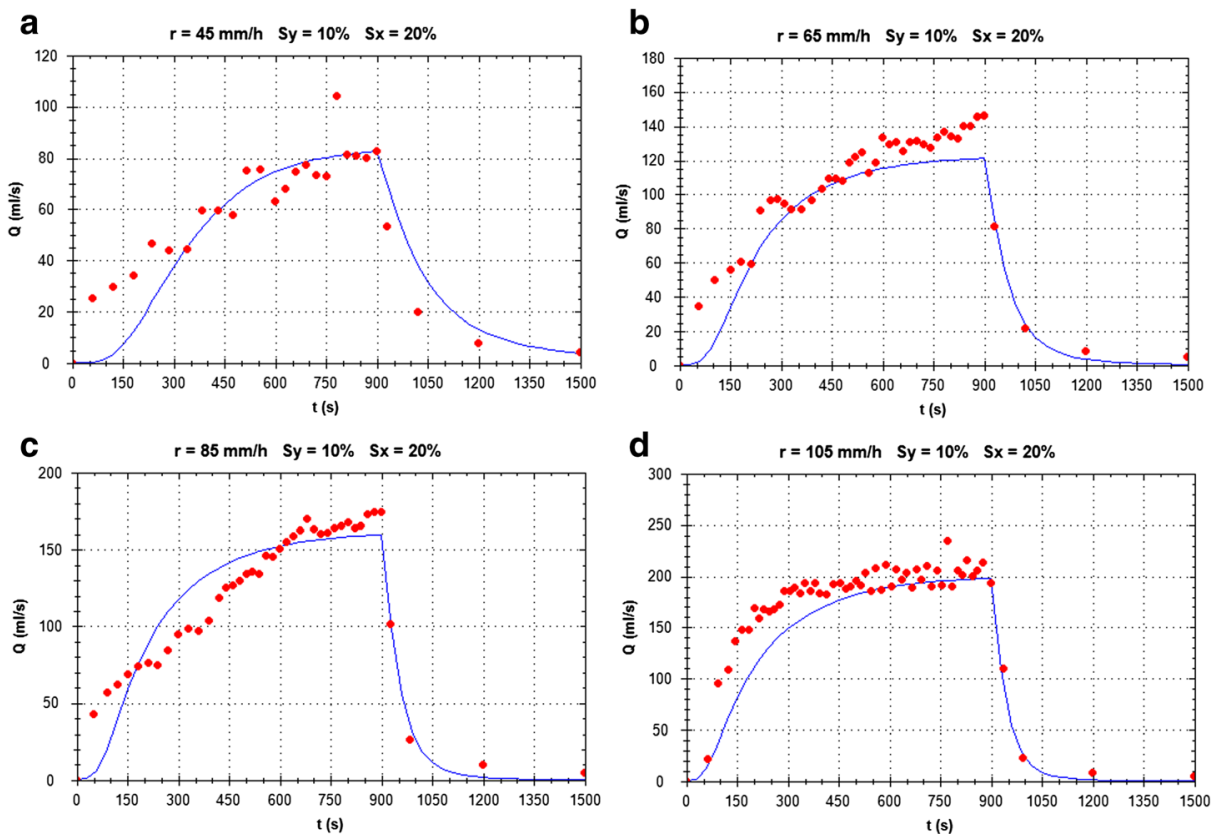

Fig. 8 Validated hydrographs against measured hydrographs for (a) $r=45 \mathrm{~mm} / \mathrm{h}, S_{y}=10 \%, S_{x}=20 \%$; (b) $r=65 \mathrm{~mm} / \mathrm{h}, S_{y}=10 \%, S_{x}=20 \%$; (c) $r=85 \mathrm{~mm} / \mathrm{h}, S_{y}=10 \%, S_{x}=20 \%$; (d) $r=105 \mathrm{~mm} / \mathrm{h}, S_{y}=10 \%$, $S_{x}=20 \%$ (Parameters used for each experiment are as in Table 3) 
Acknowledgments This study is based on the international project 'Development of a hillslope-scale sediment transport model' bilaterally supported by TUBITAK (Scientific and Technical Research Council of Turkey, project no. 108Y250) and KRF (Korea Research Foundation). Comments by the reviewers are greatly appreciated.

\section{References}

Aksoy H, Kavvas ML (2005) A review of hillslope and watershed scale erosion and sediment transport models. Catena 65:247-271

Aksoy H, Unal NE, Cokgor S, Gedikli A, Yoon J, Koca K, Inci SB, Eris E (2012) A rainfall simulator for laboratory-scale assessment of rainfall-runoff-sediment transport processes over a two-dimensional flume. Catena 98:63-72

Aksoy H, Unal NE, Cokgor S, Gedikli A, Yoon J, Koca K, Inci SB, Eris E, Pak G (2013) Laboratory experiments of sediment transport from a bare soil with rill. Hydrolog Sci J 58(7):1505-1518

Arguelles ACC, Jung M, Pak G, Aksoy H, Kavvas ML, Yoon J (2013) ) Evaluation of overland flow model for a hillslope using laboratory flume data. Water Sci Technol 68(5):1188-1194

Arguelles ACC, Jung M, Mallari KJB, Pak G, Aksoy H, Kavvas LM, Eris E, Yoon J, Lee Y, Hong S (2014) Evaluation of an erosion-sediment transport model for a hillslope using laboratory flume data. J Arid Land 6(6):647-655

Bergström S (1995) The HBV model. In: Singh VP (ed) Computer Models of Watershed Hydrology, Chapter 13, Water Resources Publications, pp 443-476

Beven KJ, Kirkby MJ (1979) A physically based, variable contributing area model of basin hydrology. Hydrolog Sci Bull 24(1):43-69

Burnash, RJC (1995) The NWS River Forecast System - Catchment Model. In: Singh VP (ed) Computer Models of Watershed Hydrology, Chapter 10, Water Resources Publications, pp 311-366

Giakoumakis S, Tsakiris G (2001) Experimental validation of a linearized kinematic wave equation for microcatchment water harvesting design. Water Resour Manag 15(4): 235-246.

Goldberg DE (1989) Genetic algorithms for search, Optimization, and machine learning. Addison-Wesley, USA.

Govindaraju RS, Kavvas ML, Tayfur G (1992) A simplified model for two-dimensional overland flows. Adv Water Resour 15(2):133-141

Horton RE (1933) The role of infiltration in the hydrological cycle. EOS T Am Geophys Un 14:446-460

Hundecha Y, Bardossy A, Werner HW (2001) Development of a fuzzy logic-based rainfall-runoff model. Hydrolog Sci J 46(3):363-376

Kavvas M, Chen Z, Dogrul C, Yoon J, Ohara N, Liang L, Aksoy H, Anderson M, Yoshitani J, Fukami K, Matsuura T (2004) Watershed Environmental Hydrology (WEHY) model based on upscaled conservation equations: hydrologic module. J Hydrol Eng 9(6):450-464

Kavvas M, Yoon J, Chen Z, Liang L, Dogrul E, Ohara N, Aksoy H, Anderson M, Reuter J, Hackley S (2006) Watershed environmental hydrology model: environmental module and its application to a california watershed. J Hydrol Eng 11(3):261-272

Lin GF, Chen LH (2004) A non-linear rainfall-runoff model using radial basis function network. J Hydrol 289(1): $1-8$

Madsen H (2000) Automatic calibration of a conceptual rainfall-runoff model using multiple objectives. J Hydrol 235(3):276-288

Mallari KJB, Arguelles ACC, Kim H, Aksoy H, Kavvas ML, Yoon J (2015a) Comparative analysis of two infiltration models for application in a physically based overland flow model. Environ Earth Sci 74(2):15791587

Mallari KJB, Kim H, Aksoy H, Yoon J (2015b) A comparison of two infiltration models applied to simulation of overland flow over a two-dimensional flume. Water Sci Technol 71(9):1325-1332

Minns AW, Hall MJ (1996) Artificial neural networks as rainfall-runoff models. Hydrolog Sci J 41(3):399-417

Post DA, Jakeman AJ (1999) Predicting the daily streamflow of ungauged catchments in SE Australia by regionalising the parameters of a lumped conceptual rainfall-runoff model. Ecol Model 123(2):91-104

Seibert J (1999) Regionalisation of parameters for a conceptual rainfall-runoff model. Agric For Meteorol 98: 279-293

Singh VP, Woolhiser DA (2002) Mathematical modeling of watershed hydrology. J Hydrol Eng 7(4):270-292

Sugawara M (1995) Tank model. In: Singh VP (ed), Computer models of watershed hydrology, Chapter 7, Water Resources Publications, 165-214

Tayfur G (2001) Modeling two-dimensional erosion process over infiltrating surfaces. J Hydrol Eng $6(3): 259-262$ 
Tayfur G (2007) Modelling sediment transport from bare rilled hillslopes by areally averaged transport equations. Catena 70(1):25-38

Tayfur G (2012) Soft computing in water resources engineering. WIT Press, Southampton, United Kingdom

Tayfur G, Kavvas ML (1998) Areally-averaged overland flow equations at hillslope scale. Hydrolog Sci J 43(3): 361-378

Yoon J, Aksoy H, Kavvas ML, Arguelles ACC, Mallari KJB (2014) A field application of physically-based erosion and sediment transport model for hillslope response. La Houille Blanche 2:81-87

Zollweg JA, Gburek WJ, Steenhuis TS (1996) SMoRMod-a GIS-integrated rainfall-runoff model. Trans ASAE 39(4):1299-1307 